\title{
Climatic drivers of dry grassland phylogenetic diversity in the Republic of Macedonia
}

\author{
Marco Antonio Batalha ${ }^{1 \star}$, Renata Ćušterevska², Vlado Matevski² \\ ${ }^{1}$ Department of Botany, Federal University of São Carlos, PO Box 676, 13565-905, São Carlos, Brazil \\ ${ }^{2}$ Institute of Biology, Faculty of Natural Sciences and Mathematics, Ss. Cyril and Methodius University, Arhimedova 3 , \\ 1000, Skopje, Macedonia
}

\begin{abstract}
Climatic gradients can be used to predict the extent to which climate drives biodiversity and to which biodiversity may be affected by global climate changes. Climate and evolutionary history are linked by the ecological adaptations of species and the history of Earth's climate. If so, phylogenetic diversity may be a good metric to estimate biodiversity. We aimed to test whether the phylogenetic diversity of Macedonian dry grasslands was related to climatic variables. We sampled 575 plots, identifying the species and building a phylogenetic tree for them. We calculated two metrics of phylogenetic diversity and regressed them against climatic variables. We also tested whether there were nodes in the tree responsible for the main observed spatial patterns of phylogenetic diversity. We found a strong signature of evolutionary history in species sorting across a gradient driven by climate in Macedonian dry grasslands. First, the amount of evolutionary history decreased towards drier and more seasonal climates, suggesting a phylogenetic niche conservatism. Second, there was an air temperature filter and a temperature seasonality filter, acting in opposite directions and leading to phylogenetic clustering. Third, there were few nodes in the phylogenetic tree with high degrees of allopatry, associated with clades that differed not only in their geographic distribution, but also in their climatic preferences. Macedonian dry grassland communities developed over centuries of traditional land use but are threatened nowadays by human activities. The use of phylogenetic approaches may lead to more effective conservation policies and help us preserve this highly diverse vegetation.
\end{abstract}

Keywords: Balkans, climate, evolutionary history, Macedonian flora, phylogeny, plant diversity

\section{Introduction}

Considering the current rates at which natural habitats are being destroyed (WWF 2016), understanding which factors influence community structure is critical to managing, preserving, and restoring biodiversity (Cavender-Bares et al. 2009). Biodiversity provides multiple environmental services and, thus, contributes to human welfare (Naeem et al. 1999). Species richness has been used as the primary method for mapping biodiversity (Marchese 2015), but, when only the number of species is taken into account as a biodiversity metric, all species are considered equally distinct (Chao et al. 2015). Community structure, however, depends not only on the number of species, but also on their ecological differences (McGill et al. 2006). Hence, the quantification of biodiversity has shifted lately from species counting to more integrative approaches, which use information about functional traits or evolutionary history or both (Marchese 2015). As a matter of fact, there has been a growing interest in including phylogenetic information into community ecology studies (Lean and Maclaurin 2016), since phylogeny has been recognised as a major source of biological variation (Jombart et al. 2010). As long as a phylogenetic tree depicts the evolutionary relations among species, it can be used to calculate the amount of evolutionary history in a community or the "phylogenetic diversity" (Lean and Maclaurin 2016). The less related the species in a community, the higher the phylogenetic diversity of that community (Vellend et al. 2011). By taking into account the evolutionary relations, phylogenetic diversity provides additional information to guide conservation decisions (Marchese 2015). For instance, assessing the loss of phylogenetic diversity may be a better indicator of community vulnerability than simply

\footnotetext{
*Corresponding author, e-mail: marcobat@fastmail.fm
} 
assessing the loss of species (Marchese 2015). Information on functional traits is often lacking, especially in species-rich communities (Webb 2000). However, if traits are conserved on the phylogeny (Ackerly 2003), closely related species are expected to play similar functional roles and tend to be limited by their similarity, and phylogenetic diversity may be used to predict community functioning (Lean and Maclaurin 2016). Phylogenetic diversity, thus, offers information on evolutionary history and potentially on functional similarity, which can shed light on the drivers of community structure and the responses of communities to environmental change (Marchese 2015). It is possible to integrate phylogenetic diversity and species distributions in site-based approaches, which quantify spatial variation in the relatedness of co-occurring species using some metric of community phylogenetic structure (Borregaard et al. 2014). Even though there are many phylogenetic diversity metrics, all of them can be grouped into three conceptual dimensions (Pavoine et al. 2009, Tucker et al. 2017): richness, the sum of accumulated phylogenetic differences among taxa in a community; divergence, the mean phylogenetic distance among taxa in a community; and regularity, the variance in distances among taxa in a community. Helmus et al. (2007), for example, developed a metric of phylogenetic richness, "phylogenetic species richness", which combines species richness and phylogenetic relatedness, and a metric of phylogenetic divergence, "phylogenetic species variability", which is independent of species richness and quantifies how, on average, species in a community are related to each other. Since ecological questions consider how accumulated differences among species are related to biodiversity patterns, these dimensions of phylogenetic diversity can be an outcome of processes under study (Tucker et al. 2017).

The fact that biodiversity varies from place to place has caught the attention not only of ecologists but of anyone who observes the natural world (Begon et al. 2006). Knowing the spatial distribution of biodiversity and what drives it are preconditions for prioritising conservation efforts on local, regional, and global scales (Begon et al. 2006). Climate, especially temperature and precipitation, has been considered the main predictor of biodiversity on a large scale (Andersen et al. 2015). The relationship between biodiversity and latitude, a surrogate for temperature, is a well-established biogeographical pattern (Kerkhoff et al. 2014) and assumed to be "ecology's oldest pattern" (Hawkins 2001). Current climatic conditions can be successfully used to predict biodiversity, especially in plants (Kerkhoff et al. 2014). Plant diversity usually peaks in warm, wet, and stable climatic conditions, declining towards cold, dry, and seasonal ones (Francis and Currie 2003). Climatic gradients can be used to predict the extent to which climate drives biodiversity and to which biodiversity may be affected by global climate changes (Andersen et al. 2015). Climatic gradients can also be used to identify sensitive zones, with high rates of compositional changes (Williams et al. 1995).

When trying to relate biodiversity and climate, species richness is generally used, but phylogenetic diversity has been increasingly taken into account (Qian et al. 2013). Since the loss of a more distinct species implies a greater loss of biodiversity than the loss of a non-distinct species with many close relatives (Purvis et al. 2000), species without close relatives may be granted special protection, so that overall evolutionary history can be maximised (Begon et al. 2006). Although climate and evolutionary history are usually considered competing explanations for biodiversity patterns, they are linked by the environmental adaptations of species and the history of Earth's climate (Kerkhoff et al. 2014). Because seed plants have been evolving since the late Devonian, about 400 million years ago (Rothwell and Erwin 1987), but temperate habitats have expanded over tropical ones only since the Oligocene, about 35 million years ago, most of the temperate clades have diversified recently (Kerkhoff et al. 2014). As a consequence, two predictions can be made: first, communities in colder, drier, and more seasonal climates will be phylogenetically less diverse and, second, clades in colder, drier, and more seasonal climates will be younger (Kerkhoff et al. 2014). In this sense, when trying to integrate phylogenetic diversity and species distributions, site-based approaches may be combined with clade-based approaches, which quantify the spatial overlap between sister clades (Borregaard et al. 2014). The simultaneous use of both approaches can be helpful to test whether environmental gradients are relevant in shaping the phylogenetic structure of local communities (Parra et al. 2010). Borregaard et al. (2014), for instance, developed a metric that uses both approaches, the "specific overrepresentation score", which goes through each node of the phylogenetic tree and compares the species richness of sister clades in each community to what is expected by chance. These scores can be summarised for all communities to produce the "geographic node divergence", which quantifies the spatial divergence between the two sister clades of a given node and identifies which nodes are mainly responsible for the observed spatial patterns of phylogenetic diversity (Borregaard et al. 2014). The use of such a metric can be a powerful strategy to detect community patterns more thoroughly and unravel the interplay of processes behind them (Graham et al. 2016).

The Republic of North Macedonia, with an area of 25,713 $\mathrm{km}^{2}$, is located in the southern portion of the Balkan Peninsula, bound by Albania to the west, Greece to the south, Bulgaria to the east, and Serbia and Kosovo to the north. Macedonia is a mountainous country, cut by valleys, canyons, and plateaus, going from $60 \mathrm{~m}$ to $2,764 \mathrm{~m}$ above sea level. From the geomorphological point of view, the country can be divided into two main regions: the western part with carbonaceous rocks and the eastern part with siliceous rocks (Čarni and Matevski 2015). Macedonia is at the top of the list of "European Hotspots" due to its great biodiversity, a result of its long historical development (Gaston and David 1994). The differentiation of indigenous species and the migration of species from other areas played an important role in its genesis, so that it is not possible to understand its current biodiversity patterns without looking at its evolutionary history (Čarni and Matevski 2015). For instance, 
glaciations during the Pleistocene in the Balkans had a significant impact on the heterogeneity of Macedonian biodiversity (Grunewald and Scheithauer 2010). Consequently, the country has a high level of endemics and relicts (Chemonics International 2001). Although Macedonia is small, the heterogeneity of its climatic conditions is very high (Bergant 2006). The country lies in a transitional zone, where climate goes from Mediterranean to continental, generally with warm summers and moderately cold winters, and annual precipitation going from $500 \mathrm{~m}$ in the eastern region to $1,700 \mathrm{~mm}$ in the western region (Filipovski et al. 1996). Southern mountains prevent hot air masses to move from south to north, whereas the Šar Mountains, located in the northwestern portion, block cold northern winds (Bergant 2006). In the highest and coldest parts, winters are long and snowy and summers are short and cold, whereas, in the warmest parts, summer temperatures reach over $40^{\circ} \mathrm{C}$ (Bergant 2006). Based on the annual cycle of mean daily air temperature and precipitation, four climatic types may be recognised in Macedonia (Filipovski et al. 1996): Mediterranean in the southeastern part, Mediterranean-continental in the central part, continental in the southwestern part, and Alpine in the northwestern part. Regions with a continental climate are expected to have the weakest response to large-scale climate change and regions with an alpine climate the strongest (Bergant 2006). Four phytogeographic regions can be distinguished, characterised by their different climates, altitudes, flora, and fauna (Chemonics International 2001): (1) SubMediterranean region, covering about $40 \%$ of the country, up to $600 \mathrm{~m}$ above sea level, characterised by the presence of Ostrya carpinifolia and Carpinus orientalis; (2) Sub-Continental region, covering about $37 \%$ of the country, between 600 and 1,200 $\mathrm{m}$ above sea level, characterised by the presence of Quercus frainetto; (3) Sub-Humid region, covering about $22 \%$ of the country, with a lower belt, between 900 and $1,250 \mathrm{~m}$ above sea level, characterised by beech forest, and a higher belt, between $1,250 \mathrm{~m}$ to $1,700 \mathrm{~m}$, with mountainous beech forest and mixed beech and fir forest; and (4) Sub-Alpine region, covering about $1 \%$ of the country, above $1,700 \mathrm{~m}$, on the highest mountains. In the first three phytogeographic regions, dry grasslands may be found (Matevski et al. 2015). Dry grasslands in Europe are mostly seminatural habitats, but they harbour some of the most diverse plant communities in the world on small scales (Janišová et al. 2011). Despite that diversity, they are one of the most endangered vegetation types in Europe due to urbanisation and afforestation (Janišová et al. 2011).

Conservation is only possible if we understand what drives community structure and dynamics in both ecological and evolutionary terms, for which phylogenetic diversity is a suitable metric (Lean and Maclaurin 2016) and climate is a potential driver (Andersen et al. 2015). Understanding what drives community structure and dynamics can also give us insights about assembly rules (Cavender-Bares et al. 2009). As long as closely related species might have similar tolerances, when the climate becomes harsher, they are more likely to occur within the same community than with less related species (Helmus et al. 2007). If so, this community would have lower phylogenetic diversity (Lean and Maclaurin 2016). By sampling dry grassland plant communities in the Republic of Macedonia, southern Balkans, calculating their phylogenetic diversity, and relating it to climatic variables, we aimed to answer three questions: (1) Does evolutionary history decrease towards colder, drier, and more seasonal climatic conditions? (2) Is environmental filtering more important in colder, drier, and more seasonal climatic conditions? (3) Are there nodes on the phylogenetic tree that identify evolutionary divergences associated with spatial segregation?

\section{Materials and methods}

We used a database consisting of 575 plots, 259 on carbonaceous rock and 316 on siliceous rock, placed on dry grasslands all over the country (Fig. 1). Each plot had $100 \mathrm{~m}^{2}$, because of the relatively homogenous vegetation at this scale. Plots were located within targeted patches of dry grasslands in such a way that edge effects were excluded (Matevski et al. 2015) and sampled according to Braun-Blanquet (1964), in late spring, the optimal phenological period of the year. Data have already been partially analysed, but with different aims (Matevski et al. 2007, 2008, 2011, 2015, Ćušterevska et al. 2012, Ćušterevska 2016). In each plot, we recorded the presence of seed plants, identifying them to species level and lodging vouchers at the MKNH herbarium, Ss. Cyril and Methodius University, Skopje, Macedonia. We used Plantminer (Carvalho et al. 2010) to search for families and synonyms concerning our sampled species. We built a phylogenetic tree for them, using Bell et al. (2010) as the backbone and improving resolution by consulting references on specific clades, as suggested by Beaulieu et al. (2012). When only the topology of the clade was available, we placed the

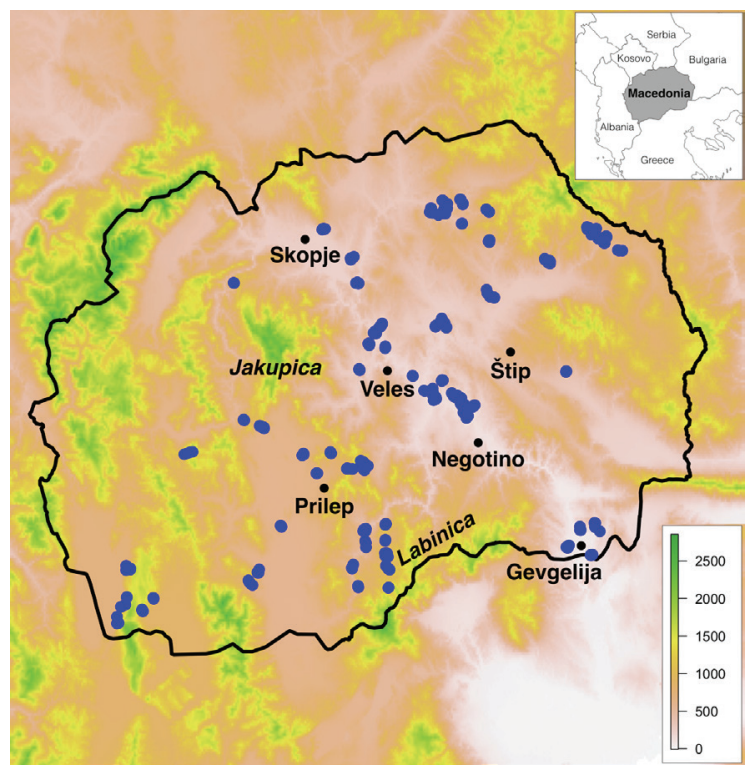

Fig. 1. Altitudinal map with the location of the examined plots (blue dots) in the Republic of North Macedonia. 
undated nodes in the tree evenly between the dated nodes (Webb et al. 2008).

Plots were placed in different altitudes, from $60 \mathrm{~m}$ to $1,500 \mathrm{~m}$ above sea level, under different climatic conditions, from Mediterranean to continental. In each plot, we recorded the coordinates with a global positioning system and, based on them, extracted altitude (Google Maps 2016) and the 19 climatic variables available on WorldClim (On-line Suppl. Tab. 1; Hijmans et al. 2005). We applied Spearman correlation analyses to test whether altitude and the climatic variables were correlated, excluding from further analyses variables highly correlated to others $(\rho>|0.7|)$. Thus, for the remaining analyses, we kept annual mean temperature (Bio 1), isothermality (Bio 3), mean temperature of wettest quarter (Bio 8), mean temperature of driest quarter (Bio 9), annual precipitation (Bio 12), and precipitation seasonality (Bio 15). These six climatic variables were related to minimum temperature, maximum temperature, precipitation, or a combination of them (On-line Suppl. Tab. 1) and brought additional information when used as explanatory variables. We standardised these six climatic variables by the range and applied a Principal Component Analysis (Jongman et al. 1995), using the first two principal components as a means to summarise the climate in the studied region.

To answer the first question, we calculated phylogenetic species ichness (Helmus et al. 2007) per plot, using the community matrix and the phylogenetic tree. This metric is directly comparable to the traditional metric of species richness but includes phylogenetic relatedness (Helmus et al. 2007) and, thus, sums up the quantity of phylogenetic differences present in a community (Tucker et al. 2017). Since our data was non-normally distributed, heteroscedastic, and with outliers, instead of applying ordinary least square regression, we applied robust regression (Huber and Ron-

Tab. 1. Phylogenetic species richness (PSR) and phylogenetic species variability (PSV) of Macedonian dry grassland communities as a function of annual mean temperature (Bio 1), isothermality (Bio 3 ), mean temperature of wettest quarter (Bio 8), mean temperature of driest quarter (Bio 9), annual precipitation (Bio 12), and precipitation seasonality (Bio 15).

\begin{tabular}{lccr}
\hline $\begin{array}{l}\text { Response } \\
\text { variable }\end{array}$ & $\begin{array}{c}\text { Explanatory } \\
\text { variable }\end{array}$ & Coefficient & \multicolumn{1}{c}{$\mathrm{P}$} \\
\hline PSR & Bio 1 & $1.44 \times 10^{-2}$ & 0.610 \\
& Bio 3 & $1.92 \times 10$ & $<0.001$ \\
& Bio 8 & $2.39 \times 10^{-3}$ & 0.716 \\
& Bio 9 & $-1.01 \times 10^{-2}$ & 0.005 \\
& Bio 12 & $1.51 \times 10^{-2}$ & 0.023 \\
& Bio 15 & $-8.08 \times 10^{-1}$ & $<0.001$ \\
\hline PSV & Bio 1 & $-1.68 \times 10^{-4}$ & $<0.001$ \\
& Bio 3 & $-2.04 \times 10^{-3}$ & $<0.001$ \\
& Bio 8 & $-2.42 \times 10^{-5}$ & $<0.001$ \\
& Bio 9 & $-1.65 \times 10^{-5}$ & $<0.001$ \\
& Bio 12 & $-1.22 \times 10^{-5}$ & 0.059 \\
& Bio 15 & $3.94 \times 10^{-4}$ & 0.062 \\
\hline
\end{tabular}

chetti 2009), with phylogenetic species richness as response variable, the six climatic variables as explanatory ones, and the bisquare algorithm as the weighting function. To answer the second question, we calculated phylogenetic species variability (Helmus et al. 2007) per plot. This metric quantifies how phylogenetic relatedness decreases the variance of some unspecified neutral trait shared by all species in the sample (Helmus et al. 2007) and, thus, represents the mean phylogenetic difference among taxa in a community (Tucker et al. 2017). We also applied robust regression following the previous procedure, but with phylogenetic species variability as response variable.

To answer the third question, we calculated the specific overrepresentation scores for all nodes in the phylogenetic tree as a measure of clade overrepresentation (Borregaard et al. 2014), with 999 randomisations. We summarised these values to calculate the geographic node divergence scores (Borregaard et al. 2014), mapping them across the plots. We used a cutoff value of 0.55 to identify which nodes were mainly responsible for the observed spatial patterns of phylogenetic diversity, also mapping them across the plots. To test whether phylogenetic spatial patterns could be explained by climate, we applied robust regressions, with the specific overrepresentation scores of the main nodes as response variables and the six climatic variables as explanatory ones. We carried out all analyses in R (R Development Core Team 2016), using the "ape" (Paradis et al. 2004), "foreign" (R Development Core Team 2015), "geiger" (Harmon et al. 2008), "ggmap" (Kahle and Wickham 2013), "MASS" (Venables and Ripley 2002), "nodiv" (Borregaard et al. 2014), "picante" (Kembel et al. 2008), "raster" (Hijmans 2015), "rgdal" (Bivand et al. 2015), and "vegan" (Oksanen et al. 2013) packages.

\section{Results}

In the 575 plots, we found 767 species, belonging to 59 families, for which we built a phylogenetic tree (On-line Suppl. Fig. 1). The richest families were Asteraceae (113 species), Fabaceae (100), and Poaceae (80), which, together, accounted for $38 \%$ of the total number of species. The first principal component of the ordination analysis explained $44 \%$ of the climatic variation, being negatively related to mean temperature of the wettest quarter and annual mean temperature and positively related especially to annual precipitation, precipitation seasonality, and isothermality (Fig. 2). According to that component, there was a climatic gradient from northeast to southwest, in which plots in the former were warmer and plots in the latter were wetter, more seasonal with respect to precipitation, and less seasonal with respect to temperature (Fig. 3a). The second principal component explained an additional $33 \%$ of the climatic variation, being negatively related especially to mean temperature of the driest quarter and positively related especially to isothermality and mean temperature of the wettest quarter (Fig. 2). According to it, there was a warmer region during the driest quarter in the central part, along the Vardar River basin, from Skopje, through Veles and Negotino, to Gevgelija (Fig. 3b). 


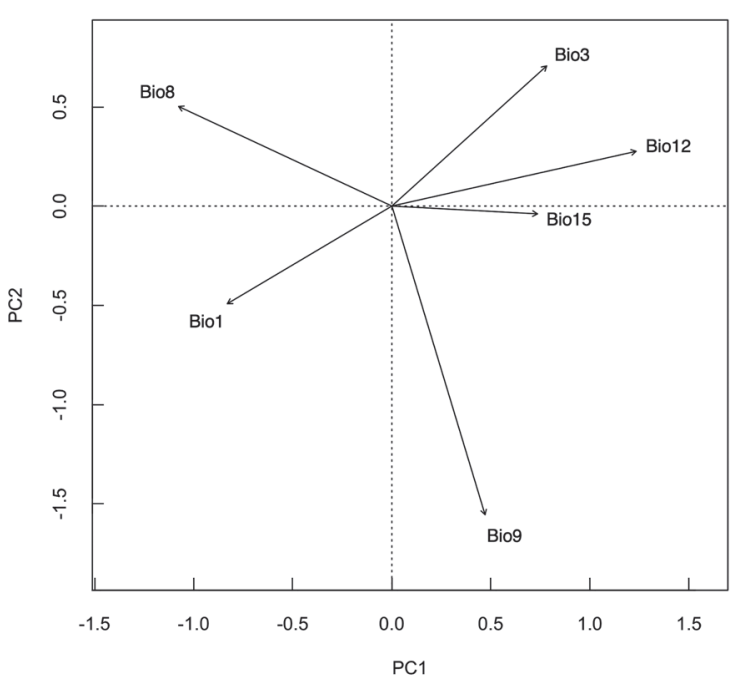

Fig. 2. Principal component analysis biplot of climatic data in the Republic of North Macedonia. Bio 1 - mean annual temperature, Bio 3 - isothermality, Bio 8 - mean temperature of wettest quarter, Bio 9 - mean temperature of driest quarter, Bio 12 - annual precipitation, Bio 15 - precipitation seasonality.

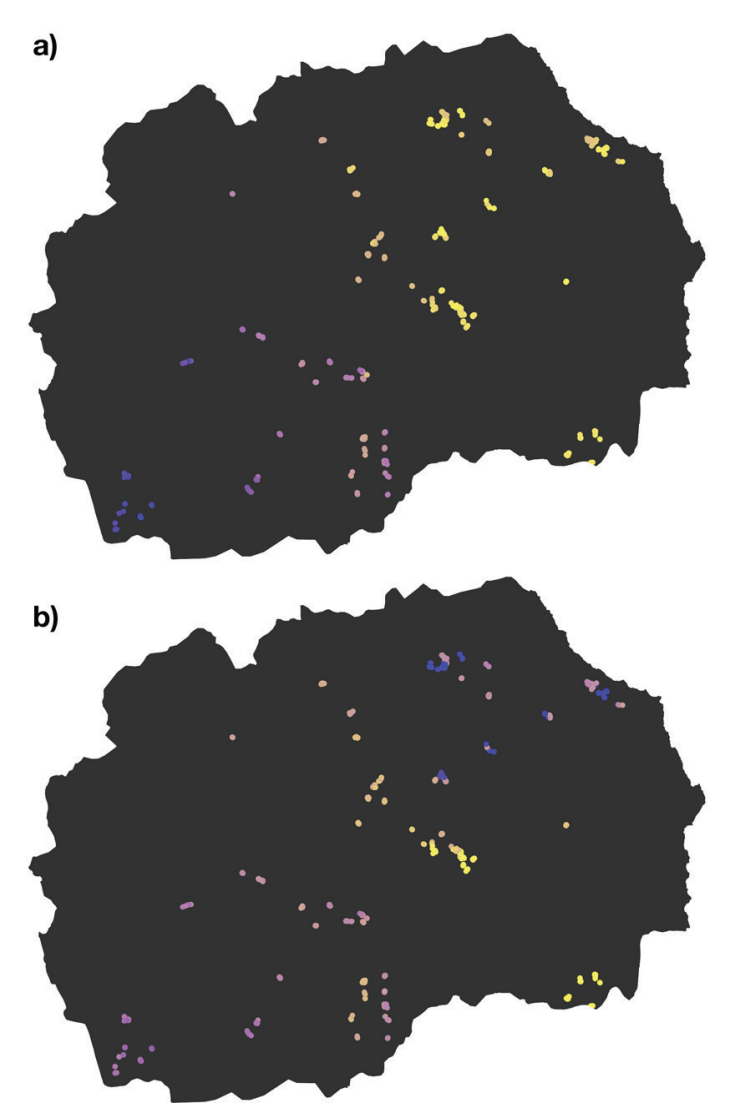

Fig. 3. Climate of the plots based on the first two principal components. (a) First component. The more yellow the point, the more negative the scores (higher annual mean temperature and mean temperature of wettest quarter); the more blue, the more positive the scores (higher annual precipitation, precipitation seasonality, and isothermality). (b) Second component. The more yellow the point, the more negative the scores (higher mean temperature of driest quarter); the more blue, the more positive the scores (higher isothermality and mean temperature of wettest quarter). Climatic data extracted from WorldClim (Hijmans et al. 2005).
Phylogenetic species richness varied from 3.9 to 37.1 , with a mean of 18.7 and a standard deviation of 5.2. We found the lowest values in the central part of Macedonia, between Veles, Štip, and Negotino, and the highest values in Kozjak Mountain near Prilep (Fig. 4a). When regressing phylogenetic species richness against the climatic variables, we found positive relationships with isothermality and annual precipitation and negative relationships with mean temperature of the driest quarter and precipitation seasonality (Tab. 1). Overall, phylogenetic species richness decreased towards warmer in the driest period, drier, and more seasonal climates. Phylogenetic species variability varied from 0.33 to 0.43 , with a mean of 0.35 and a standard deviation of 0.01 . We found low values in almost all plots, but high values in the Jakupica and Labinica mountain ranges (Fig. 4b). When regressing phylogenetic species variability against the climatic variables, we found negative relationships with annual mean temperature, isothermality, mean temperature of the wettest quarter, and mean temperature of the driest quarter (Tab. 1). Overall, phylogenetic species variability decreased towards warmer climates with less seasonal temperatures.
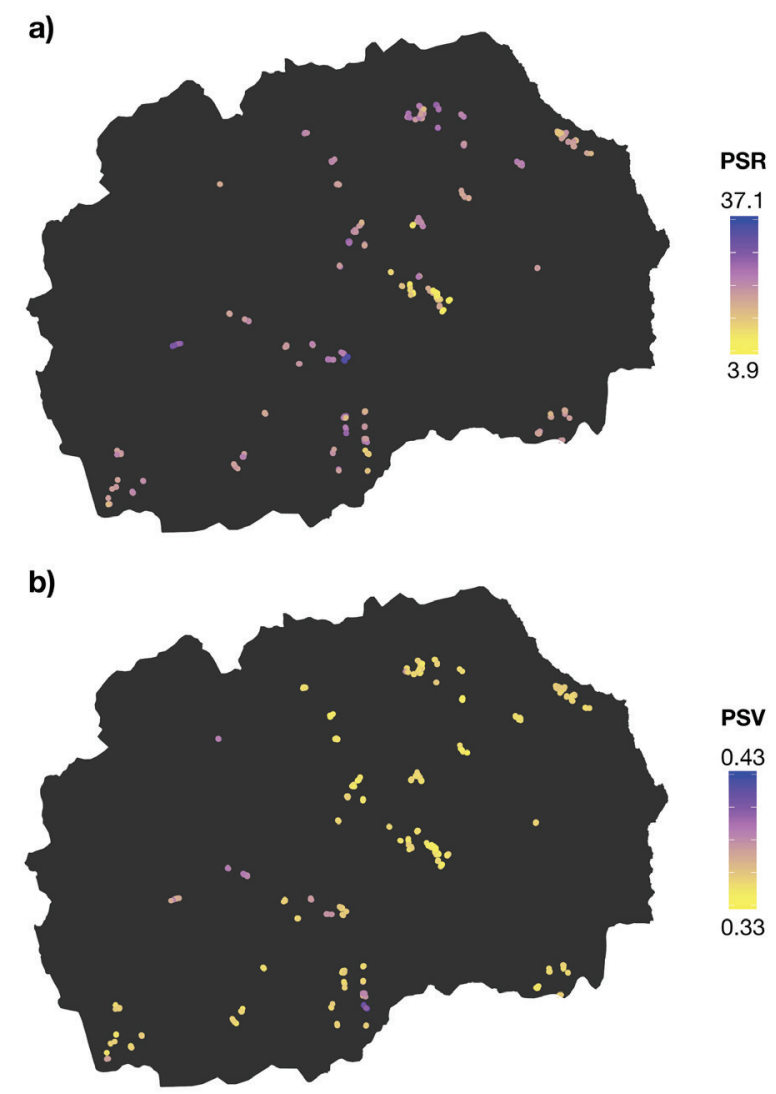

Fig. 4. Phylogenetic species richness (a) and phylogenetic species variability (b) of Macedonian dry grasslands. The more blue the point, the higher its value; the more yellow the point, the lower its value. 
Most of the nodes in the phylogenetic tree presented low geographic node divergence scores (Fig. 5). Only four nodes presented scores higher than 0.55 , corresponding to major distributional divergences in Macedonian dry grassland communities (Fig. 5). The specific overrepresentation scores for these four nodes were related to some of the climatic variables, from two to five depending on the node (Tab. 2). The first node separated Caryophyllales from Asterids, that is, Santanales, Ericales, Campanuliidae, and Lamiidae (Fig. 5). The occurrence of Asterids, with lower scores, was related to warmer climates (Figs. 6a; Tab. 2). The second node separated, within the Fabids, Malpighiales, with higher scores, related to colder climates with more seasonal temperatures, from Fabales, Fagales, and Rosales (Figs. 5 and 6 ; Tab. 2). The third node separated, within Fabaceae, Loteae, with higher scores, related to colder climates with more seasonal precipitation, from Hedysareae, Galegeae, Vicieae, and Trifolieae (Figs. 5 and 6c; Tab. 2). The fourth node separated Trifolium, with higher scores, related to drier, more isothermal climates, from other genera of Trifolieae (Figs. 5 and 6d; Tab. 2).

Tab. 2. Specific overrepresentation scores (SOS) of the four nodes with the highest degree of allopatry (see Fig. 5) as a function of annual mean temperature (Bio 1), isothermality (Bio 3), mean temperature of wettest quarter (Bio 8), mean temperature of driest quarter (Bio 9), annual precipitation (Bio 12), and precipitation seasonality (Bio 15) for Macedonian dry grassland communities.

\begin{tabular}{llrr}
\hline $\begin{array}{l}\text { Response } \\
\text { variable }\end{array}$ & $\begin{array}{c}\text { Explanatory } \\
\text { variable }\end{array}$ & Coefficient & \multicolumn{1}{c}{$\mathrm{P}$} \\
\hline SOS $_{\mathrm{A}}$ & Bio 1 & $-1.64 \times 10^{-2}$ & 0.021 \\
& Bio 3 & $5.68 \times 10^{-1}$ & $<0.001$ \\
& Bio 8 & $1.24 \times 10^{-3}$ & 0.451 \\
& Bio 9 & $-3.27 \times 10^{-3}$ & 0.002 \\
& Bio 12 & $-3.95 \times 10^{-3}$ & 0.018 \\
& Bio 15 & $-5.01 \times 10^{-2}$ & 0.354 \\
\hline SOS $_{\text {B }}$ & Bio 1 & $-2.39 \times 10^{-2}$ & $<0.001$ \\
& Bio 3 & $-8.44 \times 10^{-1}$ & $<0.001$ \\
& Bio 8 & $-6.69 \times 10^{-3}$ & $<0.001$ \\
& Bio 9 & $4.51 \times 10^{-4}$ & 0.578 \\
& Bio 12 & $1.27 \times 10^{-3}$ & 0.401 \\
& Bio 15 & $5.89 \times 10^{-3}$ & 0.904 \\
\hline SOS $_{\mathrm{C}}$ & Bio 1 & $-6.02 \times 10^{-2}$ & $<0.001$ \\
& Bio 3 & $-4.69 \times 10^{-1}$ & $<0.001$ \\
& Bio 8 & $-1.04 \times 10^{-2}$ & $<0.001$ \\
& Bio 9 & $-9.28 \times 10^{-4}$ & 0.210 \\
& Bio 12 & $-7.74 \times 10^{-3}$ & $<0.001$ \\
& Bio 15 & $3.24 \times 10^{-1}$ & $<0.001$ \\
\hline Bio 1 & $-1.57 \times 10^{-2}$ & 0.117 \\
& Bio 3 & $8.70 \times 10^{-1}$ & $<0.001$ \\
& Bio 8 & $5.78 \times 10^{-4}$ & 0.788 \\
& Bio 9 & $-7.07 \times 10^{-5}$ & 0.945 \\
& Bio 12 & $-7.21 \times 10^{-3}$ & 0.003 \\
& Bio 15 & $8.07 \times 10^{-2}$ & 0.284 \\
\hline & & &
\end{tabular}

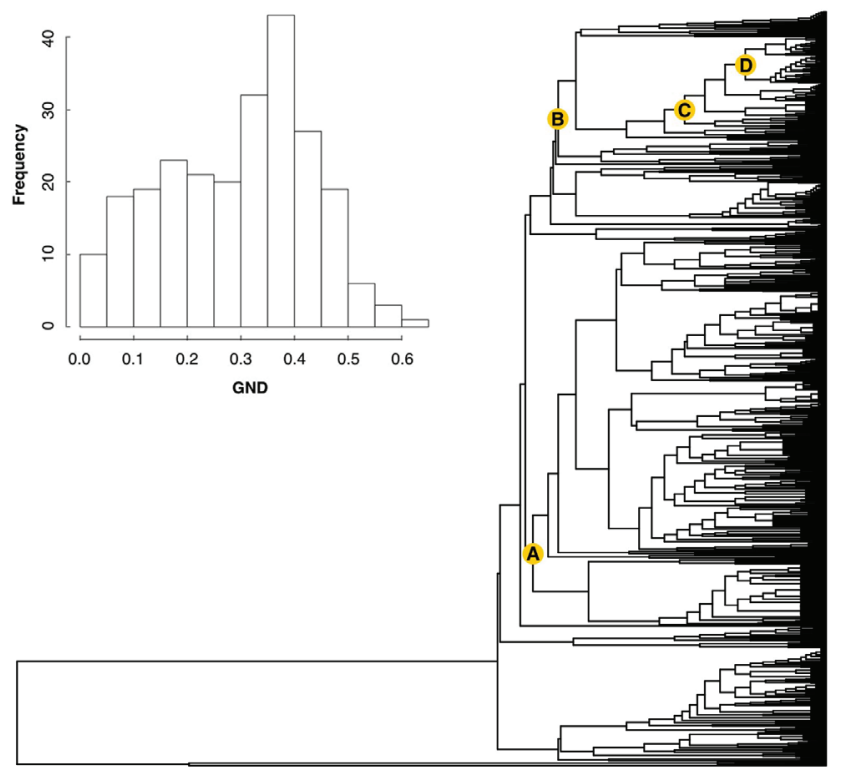

Fig. 5. Phylogenetic tree of the species sampled in Macedonian dry grasslands, showing the four nodes with the highest geographic node divergence (GND) scores. Node A separates Caryophyllales from Asterids; node B separates, within Fabids, Malpighiales from Fabales, Fagales, and Rosales; node $\mathrm{C}$ separates, within Fabaceae, Loteae from Hedysareae, Galegeae, Vicieae, and Trifolieae; node D separates Trifolium from other Trifolieae. In the detail, a histogram of all scores, showing that few nodes have high scores.
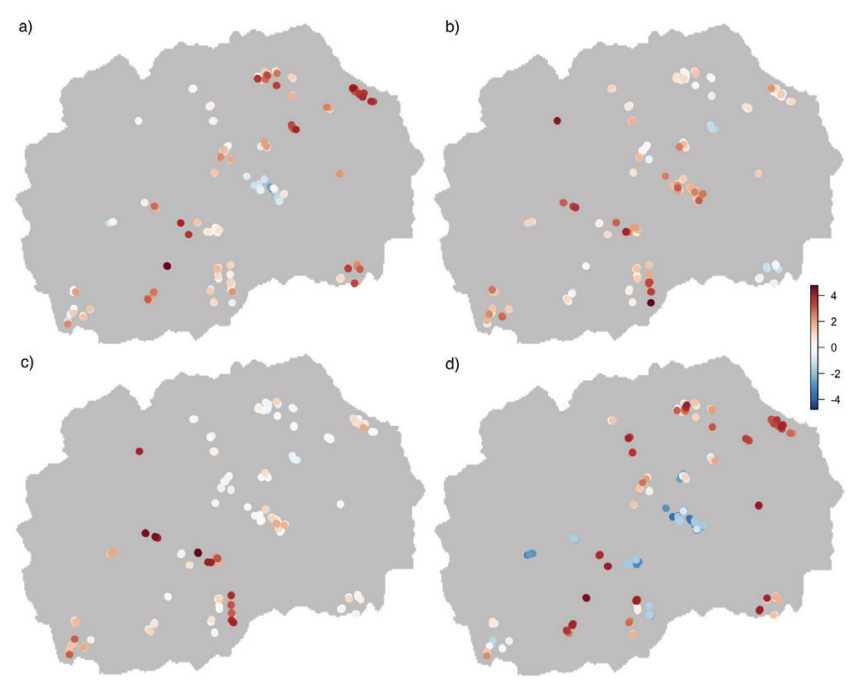

Fig. 6. Specific overrepresentation scores of the four nodes with the highest degree of allopatry (see Fig. 5). (a) node A, which separates Caryophyllales, with higher scores, from Asterids, with lower scores; (b) node B, which separates Malpighiales, with higher scores, from Fabales, Fagales, and Rosales, with lower scores; (c) node $\mathrm{C}$, which separates Loteae, with higher scores, from other tribes of Fabaceae, with lower scores; (d) node D, which separates Trifolium, with lower scores, from other genera of Trifolieae, with higher scores. Color gradation from blue to red presents the lowest to the highest scores. 


\section{Discussion}

In only 5.75 hectares, we sampled 767 species, almost one fourth of the whole Macedonian seed plant flora, which contains about 3,200 species (Matevski et al. 2003). This high number of species highlighted how diverse dry grasslands are on small scales, more diverse than wet grasslands or even tropical rainforests (Janišová et al. 2011). The main climatic pattern we found was the transition from the Mediterranean, in the eastern part of the country, to the continental climate, in the western part. Under Mediterranean influence, the climate is warmer and with more seasonal temperatures, but, as the continental influence increases, it becomes progressively colder, wetter, and with more seasonal precipitation (Bergant 2006). The high mountains in the western and southern parts prevent the influence of the Mediterranean climate from going deep into the country despite its proximity to the Aegean and Adriatic Seas (Čarni and Matevski 2015). The influence of the Aegean Sea is restricted to the Vardar River basin (Čarni and Matevski 2015), where heat waves coming from the sea make the climate warmer during the dry summer (Baldi et al. 2006), which was highlighted by the second climatic pattern we found.

Climatic variables are strong predictors for plant phylogenetic diversity (Weigelt et al. 2015). As a matter of fact, the amount of evolutionary history in Macedonian dry grassland communities, as measured by phylogenetic species richness, decreased towards drier and more seasonal climatic conditions. We found the lowest values in central Macedonia, where, during summer rains, warm and dry winds cause the water to evaporate and salt-rich sediments lead to salinised soils (Matevski et al. 2008). In this region, there is a steppe-like vegetation, with an impoverished flora able to stand the harsh conditions (Matevski et al. 2008). As climatic conditions became milder, the amount of evolutionary history increased, peaking in the Kozjak Mountain, in highland pastures, with numerous Balkan endemics (Stevanović et al. 2009, Palpurina et al. 2015). This pattern may be partially due to phylogenetic niche conservatism, that is, the idea that related species tend to occur in the same type of environment (Harvey and Pagel 1991). If many extant lineages began to diversify under tropical climatic conditions and if these lineages colonised temperate climates only recently, regions with wetter and more stable climates should be phylogenetically more diverse (Donoghue 2008).

The pattern of phylogenetic clustering, indicated by the low values of phylogenetic species variability in almost all plots, may be a signal of environmental filtering: only a few lineages of closely related species with conserved traits occurred under given climatic conditions (Hoiss et al. 2012). In Macedonian dry grasslands, temperature seems to be the main environmental filter. If phylogenetic niche conservatism holds true, we may expect decreased phylogenetic clustering when temperatures become higher and less seasonal. However, in the studied region, the warmer plots in the northeastern part were also more seasonal, whereas the colder plots in the southwestern part were also less seasonal. There appear, thus, to be two main environmental filters, acting in opposite directions: an air temperature filter, whose importance decreases from northeast to southwest, and a temperature seasonality filter, whose importance decreases from southwest to northeast. We found high values of phylogenetic species variability only in the Jakupica and Labinica mountain ranges, where the not so cold and not so seasonal climate may have led to competition as the main ecological force and, thus, to phylogenetic overdispersion (Webb 2002).

As in New World tyrant birds (Borregaard et al. 2014), the current pattern of species distributions in Macedonian dry grasslands was the outcome of major divergences at a few nodes. The most basal main node separated Asterids, more frequent in the steppe-like vegetation. Because of their derived phylogenetic position, Asterids may be considered a relatively young group that diversified during the Cretaceous (Bremer et al. 2004) and, in Macedonia, are one of the few clades able to persist in the steppe. The other three main nodes occurred along the lineage leading to presentday Fabids, one of the few seed plant lineages in which temperate species are strongly clustered (Kerkhoff et al. 2014). Even Malpighiales, typically tropical but related to colder climates in Macedonia, include some speciose genera, such as Euphorbia and Linum, that are well-known in northern temperate regions (Davis et al. 2005). These four nodes were key locations within the phylogeny in which clades differed not only in their geographic distribution, but also in their climatic preferences. These geographical shifts accompanied by climatic shifts might indicate that adaptation to new environments allows clades to colonise new areas (Borregaard et al. 2014).

In the last 40 years, Macedonia has experienced a slight increase in temperature and a decrease in precipitation (Čarni and Matevski 2015). Climate change projections for the country in the 21 st century predict a more intensive increase in temperature in summer than in winter, almost no change in winter precipitation, and a strong decrease in summer precipitation (Bergant 2006, Karanfilovski 2012). Moreover, changes are expected to be more pronounced in a Mediterranean than in a continental climate (Bergant 2006). Biodiversity is subject to the impact of global changes and reacts to these changes with its own adaptive capacity or migrating to other areas with more suitable conditions (Čarni and Matevski 2015). In this sense, we may predict: (1) a decrease in phylogenetic diversity of dry grasslands, especially in the eastern part of the country, under a Mediterranean climate; (2) an increased pattern of phylogenetic clustering due to the higher summer temperatures and lower summer precipitation; (3) major geographical shifts of the clades associated with the nodes with a high degree of allopatry; (4) an increase in phylogenetic diversity in lowland areas due to transhumance, which may have brought species with different origins and evolutionary history (Chang 1993). Under this scenario, phylogenetic diversity should be also considered when selecting priority conservation areas (Zhang et al. 2015).

The increasing availability of phylogenetic data and computational tools has stimulated the inclusion of phylogenetic 
information in community ecology (Cavender-Bares et al. 2009). We found a strong signature of evolutionary history in species sorting across a gradient driven by climate in Macedonian dry grasslands. First, the amount of evolutionary history decreased towards drier and more seasonal climates, suggesting a phylogenetic niche conservatism. Second, there appear to be an air temperature filter and a temperature seasonality filter, acting in opposite directions and leading to phylogenetic clustering. Third, there were few nodes in the phylogenetic tree with a high degree of allopatry, associated with clades that differed not only in their geographic distribution, but also in their climatic preferences. Most European dry grassland communities, including those in Macedonia,

\section{References}

Ackerly, D. D., 2003: Community assembly, niche conservatism and adaptive evolution in changing environments. International Journal of Plant Sciences 16, S165-S184.

Andersen, A. N., Toro, I., Parr, C. L., 2015: Savanna ant species richness is maintained along a bioclimatic gradient of increasing latitude and decreasing rainfall in northern Australia. Journal of Biogeography 42, 2313-2322.

Baldi, M., Dalu, G., Maracchi, G., Pasqui, M., Cesarone, F., 2006: Heat waves in the Mediterranean: a local feature or a largerscale effect? International Journal of Climatology 26, 14771487.

Beaulieu, J. M., Ree, R. H., Cavender-Bares, J., Weiblen, G. D., Donoghue, M. J., 2012: Synthesizing phylogenetic knowledge for ecological research. Ecology 93, S4-S13.

Begon, M., Townsend, C. R., Harper, J. L., 2006: Ecology: from individuals to ecosystems. Blackwell, Malden.

Bell, C. D., Soltis, D. E., Soltis P. S., 2010: The age and diversification of the angiosperms re-revisited. American Journal of Botany 97, 1296-1303.

Bergant, K., 2006: Climate change scenarios for Macedonia. University of Nova Gorica, Nova Gorica.

Bivand, R., Keitt, T., Rowlingson, B., 2015: Rgdal: bindings for the geospatial data abstraction library. R Foundation for Statistical Computing, Vienna. Retrieved from http://CRAN.Rproject.org $/$ package $=$ rgdal.

Borregaard, M. K., Rahbek, C., Fjeldså, J., Parra, J. L., Whittaker, R. J., Graham, C. H., 2014: Node-based analysis of species distributions. Methods in Ecology and Evolution 5, 1225-1235.

Braun-Blanquet, J., 1964: Pflanzensoziologie: Grundzüge der Vegetationskunde. Springer, Vienna.

Bremer, K., Friis, E. M., Bremer, B., 2004: Molecular phylogenetic dating of asterid flowering plants shows early Cretaceous diversification. Systematic Biology 53, 496-505.

Carvalho, G. H., Cianciaruso, M. V., Batalha, M. A., 2010: Plantminer: a web tool for checking and gathering plant species taxonomic information. Environmental Modelling and Software $25,815-816$.

Cavender-Bares, J., Kozak, K. H., Fine, P. A., Kembel, S. W., 2009: The merging of community ecology and phylogenetic biology. Ecology Letters 12, 693-715.

Chang, C., 1993: Pastoral transhumance in the southern Balkans as a social ideology: ethnoarcheological research in northern Greece. American Anthropologist 95, 687-703.

Chao, A., Chiu, C. H., Hsieh, T. C., Davis, T., Nipperess, D. A., Faith, D. P., 2015: Rarefaction and extrapolation of phylogenetic diversity. Methods in Ecology and Evolution 6, 380-388. are semi-natural habitats, which developed over centuries of traditional land use but are threatened nowadays by human activities (Janišová et al. 2011). The use of phylogenetic approaches in large-scale prediction of community structure and dynamics may lead to more effective conservation policies and help us preserve these highly diverse dry grasslands.

\section{Acknowledgments}

We are grateful to the Macedonian Academy of Sciences and Arts, for financial support of the research, and to the Brazilian National Council for Scientific and Technological Development (CNPq), for the productivity fellowship granted to the first author.

Chemonics International, 2001: Biodiversity assessment for Macedonia. Chemonics International, Washington.

Čarni, A., Matevski, V., 2015: Impact of climate change on mountain flora and vegetation in the Republic of Macedonia (central part of the Balkan Peninsula). In: Öztürk, M., Hakeem, K. R., Faridah-Hanum, I., Efe, R. (eds.), Climate change impacts on high-altitude ecosystems, 189-213. Springer, Cham.

Ćušterevska, R., 2016: Dry grassland vegetation in the Galičica Mountain (SW Macedonia). Contributions, Section of Natural, Mathematical and Biotechnical Sciences 37, 105-126.

Ćušterevska, R., Matevski, V., Kostadinovski, M., Čarni, A., 2012: Dry grasslands communities of Erysimo-Trifolietum in the north-eastern part of the Republic of Macedonia. Hacquetia 11, 91-111.

Davis, C. C., Webb, C. O., Wurdack, K. J., Jaramillo, C. A., Donoghue, M. J., 2005: Explosive radiation of Malpighiales supports a mid-Cretaceous origin of modern tropical rain forests. American Naturalist 165, E36-E65.

Donoghue, M. J., 2008: A phylogenetic perspective on the distribution of plant diversity. Proceedings of the National Academy of Science 105, 11549-11555.

Filipovski, G., Rizovski, R., Ristevski, P., 1996: The characteristic of the climate-vegetation-soil zones (regions) in the Republic of Macedonia. Macedonian Academy of Sciences and Arts, Skopje.

Francis, A. P., Currie, D. J., 2003: A globally consistent richnessclimate relationship for angiosperms. American Naturalist 161, 523-536.

Gaston, K. J., David, R., 1994: Hotspots across Europe. Biodiversity Letters 2, 108-116.

Graham, C. H., Machac, A., Storch, D., 2016: Phylogenetic scale in ecology and evolution. BioRxiv: 10.1101/063560.

Grunewald, K., Scheithauer, J., 2010: Europe’s southernmost glaciers: response and adaptation to climate change. Journal of Glaciology 56, 129-142.

Harmon, L. J., Weir, J. T., Brock, C. D., Glor, R. E., Challenger, W., 2008: Geiger: investigating evolutionary radiations. Bioinformatics 24, 129-131.

Harvey, P. H., Pagel, M., 1991: The comparative method in evolutionary biology. Oxford University, Oxford.

Hawkins, B. A., 2001: Ecology's oldest pattern? Trends in Ecology and Evolution 16, 470.

Helmus, M. R., Bland, T. J., Williams, C. K., Ives, A. R., 2007: Phylogenetic measures of biodiversity. American Naturalist 169, E68-E83. 
Hijmans, R. J., 2015: Raster: geographic data analysis and modeling. R Foundation for Statistical Computing, Vienna. Retrieved from: http://CRAN.R-project.org/package=raster.

Hijmans, R. J., Cameron, S. E., Parra, J. L., Jones, P. G., Jarvis, A., 2005: Very high resolution interpolated climate surfaces for global land areas. International Journal of Climatology 25, 1965-1978.

Hoiss, B., Krauss, J., Potts, S. G., Roberts, S., Steffan-Dewenter, I., 2012; Altitude acts as an environmental filter on phylogenetic composition, traits and diversity in bee communities. Proceedings of the Royal Society B 79, 4447-4456.

Huber, P. J., Ronchetti, E. M., 2009: Robust statistics. John Wiley, New Jersey.

Janišová, M., Bartha, S., Kiehl, K., Dengler, J., 2011: Advances in the conservation of dry grasslands: Introduction to contributions from the seventh European Dry Grassland Meeting. Plant Biosystems 145, 507-513.

Jombart, T., Pavoine, S., Devillard, S., Pontier, D., 2010: Putting phylogeny into the analysis of biological traits: a methodological approach. Journal of Theoretical Biology 264, 693-701.

Jongman, R. H. G., Braak, C. J. F., Tongeren, O. F. R., 1995: Data analysis in community and landscape ecology. Cambridge University, Cambridge.

Kahle, D., Wickham, H., 2013: Ggmap: spatial visualization with ggplot2. R Journal 5, 144-161.

Karanfilovski, A., 2012: Climate change scenarios for Macedonia. Ministry of Agriculture, Forestry and Water Economy, Skopje.

Kembel, S. W., Cowan, P. D., Helmus, M. R., Cornwell, W. K., Morlon, H., Ackerly, D. D., Blomberg, S. P., Webb, C. O., 2010: Picante: $\mathrm{R}$ tools for integrating phylogenies and ecology. Bioinformatics 26, 1463-1464.

Kerkhoff, A. J., Moriarty, P. E., Weiser, M. D., 2014: The latitudinal species richness gradient in New World woody angiosperms is consistent with the tropical conservatism hypothesis. Proceedings of the National Academy of Sciences 111, 8125-8130.

Lean, C., Maclaurin, J., 2016: The value of phylogenetic diversity. Topics in Biodiversity and Conservation 14, 19-37.

Marchese, C., 2015: Biodiversity hotspots: A shortcut for a more complicated concept. Global Ecology and Conservation 3, 297-309.

Matevski, V., Petkovski, S., Andonov, S., Melovski, L., Krstić, S., 2003: Country study for biodiversity of the Republic of Macedonia. Ministry of Environmental and Physical Planning, Skopje.

Matevski, V., Lozanovski, R., Kostadinovski, M., 2007: SileneThymetum ciliatopubescentis ass. nova in the vegetation on highland pastures in the Republic of Macedonia. In: Filipovski, G., Lozanovski, R., Matevski. V. (eds.), Collection of papers devoted to academician Kiril Micevski. Macedonian Academy of Sciences and Arts, Skopje.

Matevski, V., Čarni, A., Kostadinovski, M., Košir, P., Šilc, U., Zelnik, I., 2008: Flora and vegetation of the Macedonian steppe. Založba, Ljubljana.

Matevski, V., Čarni, A., Avramoski, O., Juvan, N., Kostadinovski, M., Košir, P., Marinšek, A., Paušič, A., Šilc, U., 2011: Forest vegetation of the Galičica mountain range in Macedonia. Založba, Ljubljana.

Matevski, V., Čarni, A., Ćušterevska, R., Kostadinovski, M., Mucina, L., 2015: Syntaxonomy of the rocky grasslands on carbonate bedrocks in the west and southwest of the Republic of Macedonia. Applied Ecology and Environmental Research 13, 1197-1214.

McGill, B. J., Enquist, B. J., Weiher, E., Westoby, M., 2006: Rebuilding community ecology from functional traits. Trends in Ecology and Evolution 21, 178-185.
Naeem, S., Chapin III, C. F. S., Costanza, R., Ehrlich, P. R., Golley, F. B., Hooper, D. U., Lawton, J. H., O'Neill, R. V., Mooney, H. A., Sala, O. E., Symstad, A. J., Tilman, D., 1999: Maintaining natural life support processes. Issues in Ecology 4, 2-11.

Oksanen, J., Blanchet, F. G., Kindt, R., Legendre, P., Minchin, P. R., O'Hara, R. B., Simpson, G. L., Solymos, P., Stevens, M. H. H., Wagner, H., 2013: Vegan: community ecology package. R Foundation for Statistical Computing, Vienna. Retrieved from http://CRAN.R-project.org/package=vegan.

Palpurina, S., Chytrý, M., Tzonev, R., Danihelka, J., Axmanová, I., Merunková, K., Duchon, M., Karakiev, T., 2015: Patterns of fine-scale plant species richness in dry grasslands across the eastern Balkan Peninsula. Acta Oecologica 63, 36-46.

Paradis, E., Claude, J., Strimmer, K., 2004: APE: analyses of phylogenetics and evolution in $\mathrm{R}$ language. Bioinformatics 20 , 289-290.

Parra, J. L., McGuire, J. A., Graham, C. A., 2010: Incorporating clade identity in analyses of phylogenetic community structure: an example with hummingbirds. American Naturalist $176,573-587$.

Pavoine, S., Love, M. S., Bonsall, M. B., 2009: Hierarchical partitioning of evolutionary and ecological patterns in the organization of phylogenetically-structured species assemblages: application to rockfish (genus: Sebastes) in the Southern California Bight. Ecology Letters 12, 898-908.

Purvis, A., Agapow, P. M., Gittleman, J. L., Mace, G. M., 2000: Nonrandom extinction and the loss of evolutionary history. Science 288, 328-330.

Qian, H., Zhang, Y., Zhang, J., Wang, X., 2013: Latitudinal gradients in phylogenetic relatedness of angiosperm trees in North America. Global Ecology and Biogeography 22, 1183-1191.

R Development Core Team, 2015: Foreign: read data stored by Minitab, S, SAS, SPSS, Stata, Systat, Weka, dBase. R Foundation for Statistical Computing, Vienna. Retrieved from http:// CRAN.R-project.org/package=foreign .

R Development Core Team, 2016: R: A language and environment for statistical computing. R Foundation for Statistical Computing, Vienna. Retrieved from http://www.r-project.org.

Rothwell, G. W., Erwin, D. M., 1987: Origin of seed plants: an aneurophyte-seed fern link elaborated. American Journal of Botany 74, 970-973.

Stevanović, V., Matevski, V., Tan, K., 2009: Helianthemum marmoreum (Cistaceae), a new species from the Central Balkans. Botanica Serbica 33, 13-19.

Tucker, C. M., Cadotte, M. W., Carvalho, S. B., Davies, T. J., Ferrier, S., Fritz, S. A., Grenyer, R., Helmus, M. R., Jin, L. S., Mooers, A. O., Pavoine, S., Purschke, O., Redding, D. W., Rosauer, D. F., Winter, M., Mazel, F., 2017: A guide to phylogenetic metrics for conservation, community ecology and macroecology. Biological Reviews 92, 698-715.

Vellend, M., Cornwell, W. K., Magnuson-Ford, K., Mooers, A. O., 2011: Measuring phylogenetic biodiversity. In: Magurran, A. E., McGill, B. J. (eds.), Biological diversity: frontiers in measurement and assessment, 193-206. Oxford University, Oxford.

Venables, W. N., Ripley, B. D., 2002: Modern applied statistics with S. Springer, New York.

Webb, C. O., 2000: Exploring the phylogenetic structure of ecological communities: an example for rain forest trees. American Naturalist 156, 145-155.

Webb, C. O., 2002: Phylogenies and community ecology. Annual Review of Ecology and Systematics 33, 475-505.

Webb, C. O., Ackerly, D. D., Kembel, S. W., 2008: Phylocom: software for the analysis of phylogenetic community structure and trait evolution. Bioinformatics 24, 2098-2100. 
Weigelt, P., Kissling, W. D., Kisel, Y., Fritz, S. A., Karger, D. N., Kessler, M., Lehtonen, S., Svenning, J. C., Kreft, H., 2015: Global patterns and drivers of phylogenetic structure in island floras. Scientific Reports 5, 12213.

Williams, R. J., Cook, G. D., Braithwaite, R. W., Andersen, A. N., Corbett, L. K., 1995: Australia’s wet-dry tropics: identifying the sensitive zones. In: Pernetta, J., Leemans, R., Elder, D.,
Humphrey, S. (eds.), The impact of climate change on ecosystems and species: terrestrial ecosystems, 39-65. IUCN, Gland. WWF, 2016: Living planet report. WWF International, Gland.

Zhang, J., Nielsen, S. E., Stolar, J., Chen, Y., Thuiller, W., 2015: Gains and losses of plant species and phylogenetic diversity for a northern high-latitude region. Diversity and Distributions 21, 1441-1454. 